\title{
O DESENVOLVIMENTO DE METODOLOGIAS PARA O ENSINO DE BIOLOGIA COM INCLUSÃO DE TECNOLOGIAS DIGITAIS NO ENSINO PÚBLICO
}

\author{
THE DEVELOPMENT OF METHODOLOGIES FOR TEACHING BIOLOGY WITH \\ THE INCLUSION OF DIGITAL TECHNOLOGIES IN PUBLIC EDUCATION
}

\section{Ivancia Donato de Luna Sousa ${ }^{1}$}

RESUMO: Para o cidadão do século XXI, é fundamental lidar com as tecnologias digitais para se comunicar e se apropriar da informação disponível na rede. É nesse contexto sociocultural que vivem nossos de jovens, obtendo informações de forma rápida, recorrendo primeiro às fontes digitais, antes de procurarem-na em livros ou em mídia impressa. No entanto, preparar o cidadão do século XXI significa dar elementos para que ele possa utilizar as tecnologias digitais da melhor maneira possível, sabendo transformar a informação em conhecimento. Do ponto de vista da operacionalização básica dos aparelhos, as novas gerações não demonstram dificuldades. No entanto, quando precisam buscar informações em locais confiáveis, selecionar corretamente materiais pertinentes, articular as informações entre si para construir conhecimento e empregar esses recursos na compreensão do seu cotidiano, nem sempre obtêm sucesso. Nesse caso, o papel da Educação e da escola são fundamentais no sentido de oferecer ferramentas para tornar o uso do digital produtivo em termos da formação da criação conhecimentos do aluno, de maneira reflexiva e consistente. Este trabalho mostra o desenvolvimento de metodologias para inclusão destas tecnologias em sala de aula, de forma que nesse sentido, acredita-se que as soluções digitais estão no centro das transformações sociais vividas e que elas podem ser motivadoras e integradoras de uma sólida proposta educativa, por sua capacidade de enriquecimento dos processos pedagógicos e pela atratividade que o mundo digital exerce nas novas gerações em formação.

Palavras-chave: Tecnologia. Inovação. Inclusão. Educação.

ABSTRACT: For citizens of the 2ist century, it is essential to deal with digital technologies to communicate and appropriate the information available on the network. It is in this sociocultural context that our youth live, obtaining information quickly, using digital sources first, before looking for it in books or in print. However, preparing the citizens of the 2ist century means providing elements so that they can use digital technologies in the best possible way, knowing how to transform information into knowledge. From the point of view of the basic operationalization of the devices, the new generations do not show difficulties. However, when they need to search for information in reliable places, correctly select relevant materials, articulate the information with each other to build knowledge and use these resources to understand their daily lives, they are not always successful. In this case, the role of Education and the school are fundamental in the sense of offering tools to make the use of digital productive in terms of the formation of the student's knowledge creation, in a reflective and consistent way. This work shows the development of methodologies for the inclusion of these technologies in the classroom, so that in this sense, it is believed that digital solutions are at the center of the social transformations experienced and that they can be motivating and integrating a solid educational proposal, for its capacity to enrich the pedagogical processes and for the attractiveness that the digital world has in the new generations in formation.

\footnotetext{
${ }^{1}$ Graduada Ciências Biológicas (Bacharel e Licenciatura) pela Universidade Federal da Paraíba- UFPB, mestre em Biologia Celular e Molecular pela Universidade Federal da Paraíba e professora do Quadro Efetivo do Estado da Paraíba na Escola Cidadã Integral Liceu Paraibano. E-mail: ivanciadr@gmail.com.
} 
Keywords: Technology. Innovation. Iinclusion. Education.

\section{INTRODUÇÃO}

Desde a popularização da internet no Brasil e a chegada da cultura digital, as pessoas de todas as idades usam esses recursos como ferramentas de acesso a entretenimento, comunicação e serviços, com isso nos mantemos conectados o tempo todo, portanto, vivemos em uma sociedade imersa em uma cultura digital como mediadora das relações humanas. Os recursos eletrônicos estão disponíveis no cotidiano, tendo os alunos um contato direto e constante com esses materiais, o que para muitos educadores pode ser um problema em sala de aula.

Atualmente um aparelho celular smartphone permite acessar desde as redes sociais aos mais diferentes aplicativos que possibilitam diversas funções como ler um livro, e-mails, pedir taxi, fazer compras, trocar mensagens instantâneas com diferentes lugares do mundo, etc. Para Castells (2009), a comunicação como mediadora entre as relações humanas é um fator determinante na definição de cultura digital onde habilidade para se comunicar em tempo real, bem como a existência de várias modalidades de se dá a comunicação e a interconexão das redes digitais são elementos definidores deste conceito.

Contudo, o conceito de cultura digital se encontra longe de estar consolidado, pois, o seu uso ainda é muito recente. Nesse sentido, a visão de Prado (2009) é de que a cultura digital define aspectos amplos na transformação da sociedade contemporânea, pois para ele:

A cultura digital é a cultura do século XXI. É a nova compreensão de praticamente tudo. O fantástico da cultura digital é que a tecnologia trouxe à tona mudanças concretas, reais e muito práticas em relação a tudo que está acontecendo no mundo, mas também reflexões conceituais muito amplas sobre o que é a civilização e o que nós estamos fazendo aqui. (PRADO, 2009, p. 45)

Entendemos que, para o cidadão do século XXI, é fundamental lidar com as tecnologias digitais para se apropriar das informações disponíveis na rede, que é a realidade sociocultural em que vivem as novas gerações de jovens, na qual conseguem obter informações de forma rápida, recorrendo primeiro a fontes digitais e à web, antes de procurarem-na em livros ou na mídia impressa. Por isso, podemos dizer que eles "falam” a linguagem digital desde cedo, pois já vieram ao mundo ápice dos recursos eletrônicos disponíveis na vida cotidiana. (ALMEIDA,2009)

Justamente por terem um contato direto e constante com ferramentas tecnológicas e com veiculação de informações muito rápidas, dominam com tranquilidade as técnicas de uso de recursos eletrônicos como tablets, smartphones, notebooks, entre outros, não demonstrando dificuldades em sua operação, porém, quando precisam buscar informações em locais confiáveis, selecionar corretamente materiais, articular as informações entre si para construir conhecimento e empregar esses recursos na compreensão do seu cotidiano, nem sempre obtêm sucesso. Nesse 
caso, o papel da Educação e da escola são fundamentais no sentido de oferecer ferramentas para tornar o uso do digital produtivo em termos da formação da biblioteca de conhecimentos do aluno, maneira reflexiva e consistente. (ALMEIDA, 2009)

O uso da tecnologia digital, na educação, tem como princípios pedagógicos a valorização da aprendizagem significativa e ativa que possibilita o desenvolvimento da autonomia, do espírito indagativo e da aprendizagem colaborativa tornando o aluno é o protagonista na construção do conhecimento, explorando a ferramenta digital por meio de conteúdo adaptado, de forma interativa. Nesse aspecto, a escola não pode deixar de reconhecer essas transformações que modificaram as relações da humanidade do ponto de vista social, econômico e até existencial, pois ela é a responsável pela educação dessa geração onde o currículo escolar não pode continuar dissociado das novas possibilidades tecnológicas. (ALMEIDA e SILVA 20II).

No entanto, preparar o aluno, significa dar elementos para que ele possa utilizar as tecnologias digitais da melhor maneira possível, sabendo transformar essa ferramenta em conhecimento. $\mathrm{O}$ uso das ferramentas digital produtivo em termos da formação, da criação e dos conhecimentos do aluno, onde tendo o professor como mediador, oferece aos alunos condições de desenvolver habilidades como pesquisar, selecionar e avaliar informações, interagindo com os recursos transformando-os em conhecimento o que para o ensino de biologia é extremamente importante (Almeida, 2010). Além disso, para Valente, (2008) intermediar novas práticas de aprendizagem, torna a sala de aula um espaço horizontalizado, onde professores e alunos, são parceiros no processo de aprendizagem significativa.

Nesse sentido, acredita-se que as tecnologias digitais estão no centro das transformações sociais e que elas podem ser motivadoras e integradoras de uma sólida proposta educativa, por sua capacidade de enriquecimento dos processos pedagógicos e pela atratividade que o mundo digital exerce nas novas gerações em formação. Pensando assim, esse trabalho tem como objetivo geral aliar iniciativa, criatividade, interesse intelectual e curiosidade dos alunos na busca por conhecimento, em aulas de biologia para o ensino médio, desenvolvendo uma postura reflexiva e questionadora para a resolução de problemas, como base da investigação científica, onde o aluno possa responsabilizar-se pelo próprio aprendizado, de forma ativa, reflexiva e contínua.

\section{DESENVOLVIMENTO}

O projeto foi desenvolvido em três bimestres, sendo descrito da seguinte forma: o segundo bimestre do ano letivo foi o período para elaboração do projeto, na segunda metade do segundo bimestre após a apresentação do projeto e durante todo o terceiro bimestre e início do quarto bimestre, o projeto foi aplicado, já a produção do relatório final se iniciou com o projeto e foi concluído no início do quarto bimestre com a socialização dos resultados com toda 
comunidade escolar (Figurar)

Figurar: Momentos da socialização dos resultados com toda comunidade escolar;

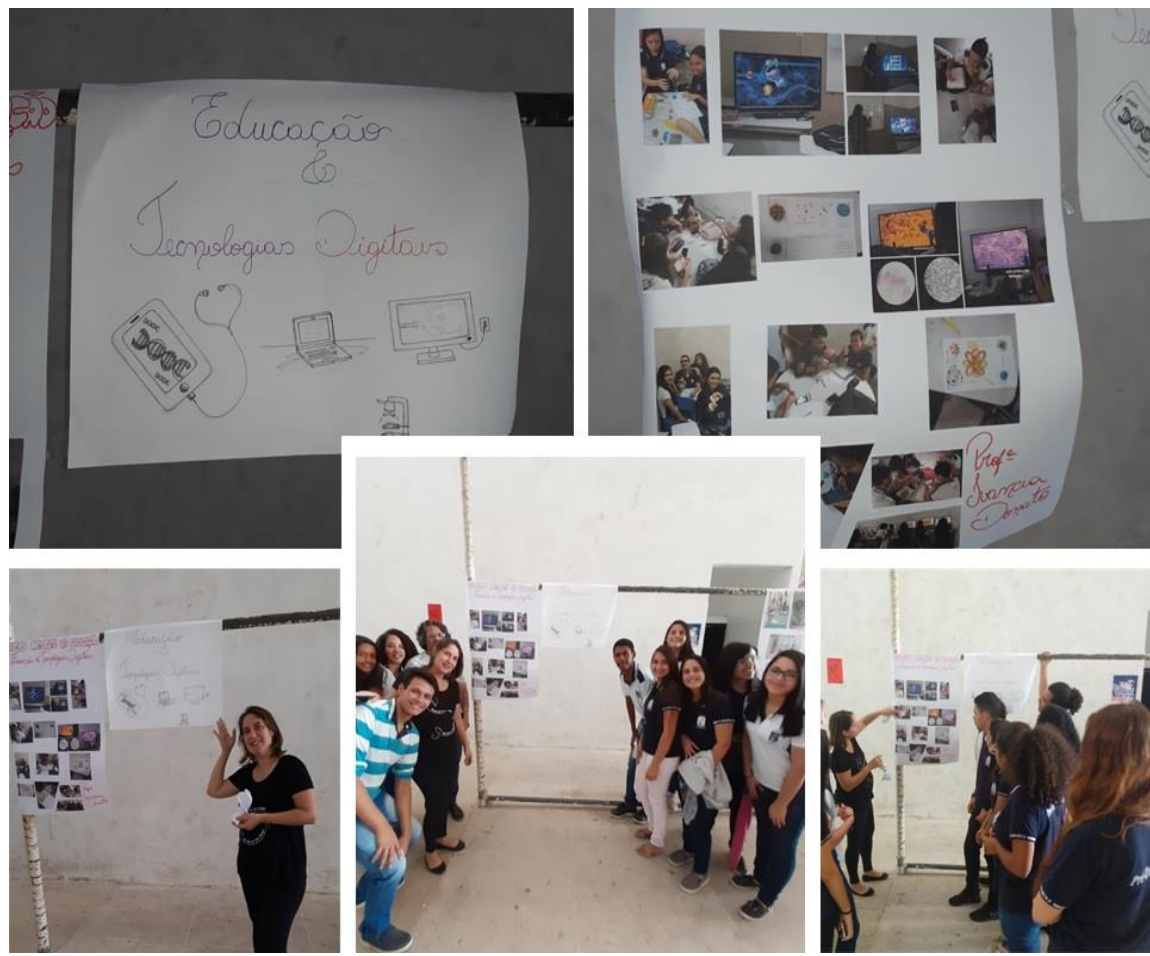

Fonte: Dados da pesquisa

A nossa proposta teve como princípios pedagógicos a valorização da aprendizagem significativa e ativa, possibilitando o desenvolvimento da autonomia e do espírito indagativo, e que aconteça também por meio da aprendizagem colaborativa. Para que estes princípios sejam utilizados de forma prática, eles foram explorados a partir da sua operacionalização através dos seguintes fatores: conhecimentos prévios dos alunos, temas disparadores, problematização, proposta de pesquisa, aluno protagonista, conteúdo adaptativo e interatividade

Os conhecimentos prévios são os conceitos iniciais relevantes que estão presentes na estrutura cognitiva do aluno funcionando como estruturas nas quais os novos conhecimentos irão se integrar, onde o sucesso desse processo depende da relação estabelecida entre os novos conteúdos e os que o aluno já conhece, pois o aluno busca na sua estrutura cognitiva o conhecimento que irá ancorar os novos conceitos e conteúdo a serem compreendidos. Assim, os conteúdos foram se transformando durante o processo de aprendizagem, pois foram vinculados à forma como o assunto inédito foi relacionado com os já existentes no repertório do aluno, e à atribuição de significados que foram dados a eles (AUSUBEL, 200).

Os temas disparadores foram importantes estratégias pedagógicas condutoras da reflexão, pois ao partir de um problema inicial que deve ser resolvido ao longo do estudo, auxiliou 
a tornar a aprendizagem significativa para o aluno. Para Jerome Bruner (200I), a educação deve se situar no contexto dos problemas enfrentados pela sociedade e ter relação com o meio social em que vive o estudante. Portanto, deve fazer a ligação entre o mundo vivido e aquele conhecimento abstrato a ser compreendido.

A problematização foi o método no qual os alunos observaram a realidade para identificar problemas a serem pesquisados com vista as suas características e complexidade e resolvê-lo. Nesse processo foram mobilizados vários conhecimentos dos alunos, tanto os que eles já tinham como os que iriam adquirir com a experiência, onde esses puderam ser comprovados ou reformulados pelo estudo.

A proposta de pesquisa parte da dúvida e a insatisfação com o que já se sabe e foram motores fortes para disparar a vontade de conhecer mais. A formação de grupos de atuação em torno da resolução de problemas por meio da pesquisa teve o potencial de estimular esses processos por um modo de aprendizado em que os estudantes puderam construir o conhecimento coletivamente a partir de propostas de trabalho em grupo.

Utilizando as ferramentas tecnológicas o aluno pode resolver o problema em questão sem necessidade de uma aula anterior, nesse caso o espaço da sala de aula foi usado para resolver dúvidas, ou discutir com o professor e os colegas sobre algum ponto específico, tornando o aluno protagonista do seu conhecimento. Esse tipo de metodologia é chamado ensino reverso, ou aula invertida, ou ainda flipped classroom, no qual a sala de aula passa a ser a ponta final da atividade pedagógica como propõe Moran (2015), onde o aluno estuda antes os materiais básicos e os aprofunda depois em classe com a orientação do professor e a colaboração dos colegas.

Cada percurso de conhecimento foi desenvolvido para permitir que o aluno encontre desde o conteúdo mais básico e informativo, possibilitando fazer a ancoragem com o que conhece sobre o assunto, até a elaboração de conceitos mais complexos e abstratos. A proposta metodológica para apresentação do conteúdo foi desenvolvida de forma não seriada, possibilitando que o professor e alunos construíssem o currículo mais adequado à etapa de aprendizagem em questão de forma adaptativa.

A interatividade é um aspecto que foi valorizado amplamente e se referiu ao potencial de comunicação em que as tecnologias digitais desenvolveram autonomia e o protagonismo do aluno, pois, de simples receptor de informações, ele passou a interagir com os conteúdos e os objetos digitais. Por meio das Ferramentas de autoria, eles puderam produzir conteúdo, criar suas próprias experiências de aprendizagem ao interagir com experimentos em laboratórios virtuais, legendas e gráficos interativos em mapas, animações, movimentação de câmera, salvar conteúdos, marcar partes que considera mais relevantes, acrescentando ou destacando conteúdos de acordo com o seu percurso de aprendizagem e entendimento. 
Para subsidiar e auxiliar na utilização das Ferramentas digitais, propomos um programa pautado na implementação de materiais para atividades em sala de aula, que denominamos de Sequências Didáticas (SD), que são atividades organizadas e vinculadas aos conteúdos digitais e às diferentes áreas do conhecimento.

Por ter sido aplicado ao ensino da biologia, que é uma disciplina das áreas das ciências da natureza, seus conteúdos, juntamente com as ferramentas digitais, estimulam o raciocínio lógico, senso crítico, bem como a leitura e interpretação das ferramentas trabalhadas o que colaboram para um melhor desempenho do aluno em outras áreas do conhecimento científico como língua portuguesa e matemática, onde pode ser trabalhados alguns descritores dessas áreas (Figura 2) que foram de extrema importância para desenvolver competências e habilidades na áreas das ciências e da natureza propostas nas SDs (Figura 3)

Figura 2 : Descritores trabalhados em língua portuguesa

\begin{tabular}{|c|c|c|c|c|c|c|c|c|c|}
\hline \multicolumn{10}{|l|}{ Descritores } \\
\hline Língua Portuguesa & \multicolumn{2}{|c|}{ DI } & $\mathrm{D}_{2}$ & \multicolumn{2}{|l|}{ D8 } & Di3 & \multicolumn{2}{|l|}{ Di4 } & Di6 \\
\hline Matemática & DI & $\mathrm{D}_{3}$ & Di3 & Di7 & $D_{22}$ & $D_{31}$ & $D_{33}$ & $D_{34}$ & $D_{35}$ \\
\hline
\end{tabular}

Dı: Localizar informações explícitas em um texto; D2: Estabelecer relações entre partes de um texto, identificando repetições ou substituições que contribuem para a continuidade de um texto; D8: Estabelecer relação entre a tese e os argumentos oferecidos para sustentá-la; Diz: Identificar as marcas linguísticas que evidenciam o locutor e o interlocutor de um texto; Di4: Distinguir um fato da opinião relativa a esse fato; Dı6: Identificar efeitos de ironia ou humor em textos variados; Descritores trabalhados em Matemática: Di: Identificar figuras semelhantes, mediante o reconhecimento de relações de proporcionalidade $\mathrm{D}_{3}$ : Relacionar diferentes poliedros ou corpos redondos com suas planificações ou vistas. Di3: Resolver problema envolvendo a área total e/ou volume de um sólido (prisma, pirâmide, cilindro, cone e esfera). Di7: Resolver problema envolvendo equação do $2^{\circ}$ grau. D22: Resolver problema envolvendo P.A./P.G. dada a fórmula do termo geral. D3r: Determinar a solução de um sistema linear associando-o a uma matriz D33: Calcular a probabilidade de um evento. D34: Resolver problema envolvendo informações apresentadas em tabelas e/ou gráficos. D35: Associar informações apresentadas em listas e/ou tabelas simples aos gráficos que as representam e vice versa. 
Figura 3 : Competências e Habilidades das Ciências da Natureza

\begin{tabular}{|c|c|}
\hline \multicolumn{2}{|c|}{ Competências e Habilidades das Ciências da Natureza } \\
\hline Competência I & Habilidade \\
\hline $\begin{array}{l}\text { Compreender as ciências Naturais e as } \\
\text { tecnologias a elas associadas como construções } \\
\text { humanas, percebendo seus papéis nos } \\
\text { processos de produção e desenvolvimento } \\
\text { econômico e social da humanidade }\end{array}$ & $\mathrm{H}_{2} \mathrm{e}_{3}$ \\
\hline Competência 8 & Habilidade \\
\hline $\begin{array}{l}\text { Apropriar-se da biologia para, em situações- } \\
\text { problema, interpretar, avaliar ou planejar } \\
\text { intervenções científico-tecnológica. }\end{array}$ & $\mathrm{H}_{29}$ e $\mathrm{H}_{30}$ \\
\hline
\end{tabular}

Fonte: Dados da pesquisa

Na Figura 3: H2: Associar a solução de problemas de comunicação, transporte, saúde ou outro, com o correspondente desenvolvimento científico e tecnológico. $\mathrm{H}_{3}$ : Confrontar interpretações científicas com interpretações baseadas no senso comum, ao longo do tempo ou em diferentes culturas. H29: Interpretar experimentos ou técnicas que utilizam seres vivos, analisando implicações para o ambiente, a saúde, a produção de alimentos, matérias primas ou produtos industriais. $\mathrm{H}_{3} \mathrm{o}$ : Avaliar propostas de alcance individual ou coletivo, identificando aquelas que visam à preservação e a implementação da saúde individual, coletiva ou do ambiente.

A estrutura das Sequências Didáticas contempla situações de aprendizagem diversificadas, de modo que foram incorporadas no planejamento e adequadas à sua realidade local. As SDs aplicadas tiveram por base a metodologia ${ }_{5} \mathrm{E}$ como forma de tornar o Programa uma proposta totalmente aplicável na prática (ZABALA,1998).

O ciclo de aprendizagem 5 E foi desenvolvido pela Biological Sciences Curriculum Study (BSCS), que é um centro educacional cujo objetivo é realizar pesquisas e desenvolver materiais curriculares de alta qualidade nas áreas de Ciência e Tecnologia, além de fornecer suporte educacional para escolas. Esta metodologia foi adaptada para o contexto específico do Programa.

As Sequências Didáticas foram criadas, durante o planejamento pedagógico, com o intuito de criar uma situação de aprendizagem que despertasse a curiosidade e o desejo do aluno de investigar um tema ou assunto e ao mesmo tempo, ter a intenção de colocar o aluno em uma situação de aprendizagem que tenha um início acessível, mas que vá apresentando certa dificuldade para que ele possa, aos poucos, compreender o tema sem chegar antecipadamente à solução, da mesma forma como o aluno se vê diante das diferentes fases de um jogo.

As Sequências Didáticas propostas pelo Programa Inspira Digital (2016) apresentam uma série de etapas, as quais iremos abordar a seguir: 


\section{Iㅇ fase :Aproximar os mundos}

A ideia desta primeira etapa foi trazer o conteúdo que seria tema da aula para o mundo do aluno. Nessa fase despertamos o desejo, realizada cada atividade por meio da identificação dos conhecimentos prévios e do trabalho com um tema disparador, onde o aluno pode desmitificar um conhecimento previamente construído para incorporar novos conceitos ao seu repertório. É nessa fase onde pudemos trabalhar os descritores de língua portuguesa que foram propostos nesse trabalho, pois o aluno ao receber as sequências didáticas que continham uma "atividade problema” e um link de acesso onde precisam utilizar os descritores Di, D2, D8, Di3, Di4 e Di6 para que possam ler, interpretar e identificar o que cada sequência didática tinha como proposta a ser realizada, como por exemplo produção de modelos e/ou maquetes biológicas, produção textual, experimentos em laboratório, questionamento e pesquisas, entre outras atividades nas quais as competências e habilidades para o ensino de ciências da natureza, citadas anteriormente, também pudessem ser trabalhadas nessa e em todas as fases desse trabalho. (Figura 4)

Figura 4: contato inicial com as SDs: A: Construção de modelos atômicos tridimencionais $3^{\circ}$ ano; B: Origames de DNA 3 ano, C: Origames de DNA ${ }^{\circ}$ ano;

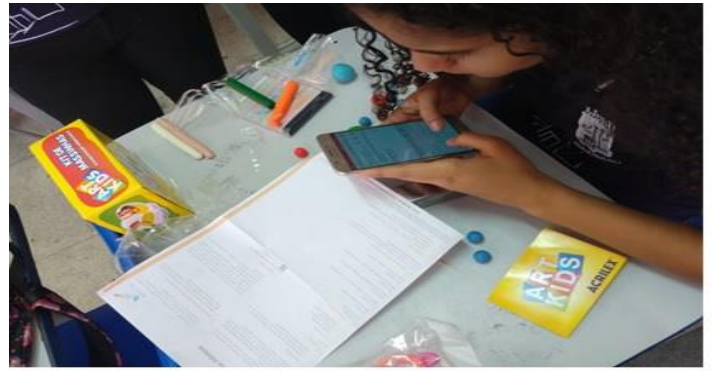

A

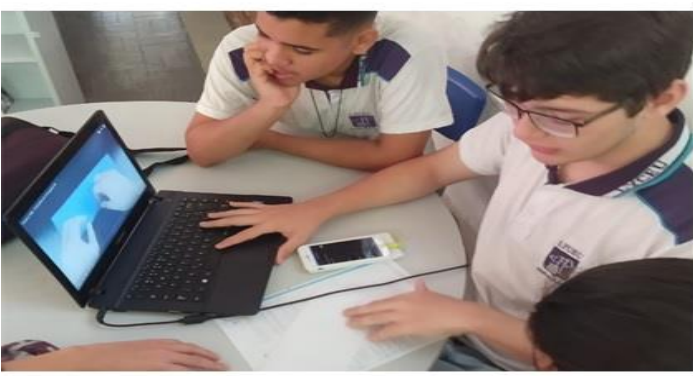

B

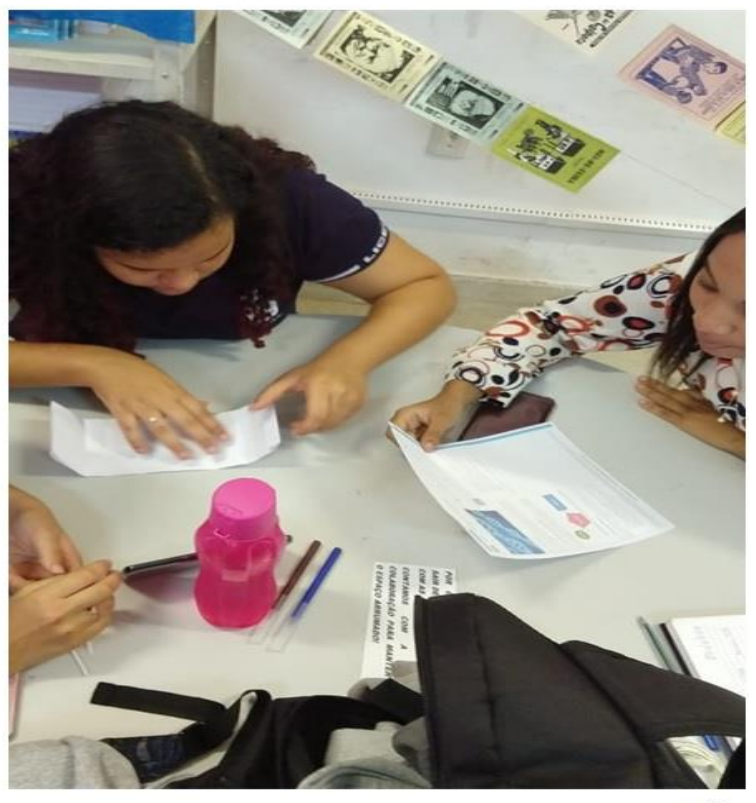

$\mathrm{C}$

Fonte: Dados da pesquisa

\section{$2^{\circ}$ Fase: Construir Ideias}

Esta etapa é a de possibilitar aos alunos ampliem experiências, construindo ideias, identificando e desenvolvendo conceitos, bem como compreendendo os processos, observando e 
questionando a partir da exploração ativa dos materiais digitais ampliando a imaginação, possibilitando com mais rapidez a formulação e o teste de hipóteses desenvolvendo assim, o espírito indagativo. É nesta fase em que as competências e habilidades propostas puderam ser trabalhadas de forma mais evidente e alguns descritores de matemática também começaram a ser trabalhados nesta etapa como Di, D34 e D35. (Figura 5)

Figura 5: A: Sala ${ }^{\circ}$ ano utilizando os recursos para entender o desafio; B: Prática de sangue conhecendo o tecido sanguineo $3^{\circ}$ ano, C: Conhecendo os diferentes modelos atômicos $3^{\circ}$ ano; e D:Entendendo probabilidade genética $3^{\circ}$ ano

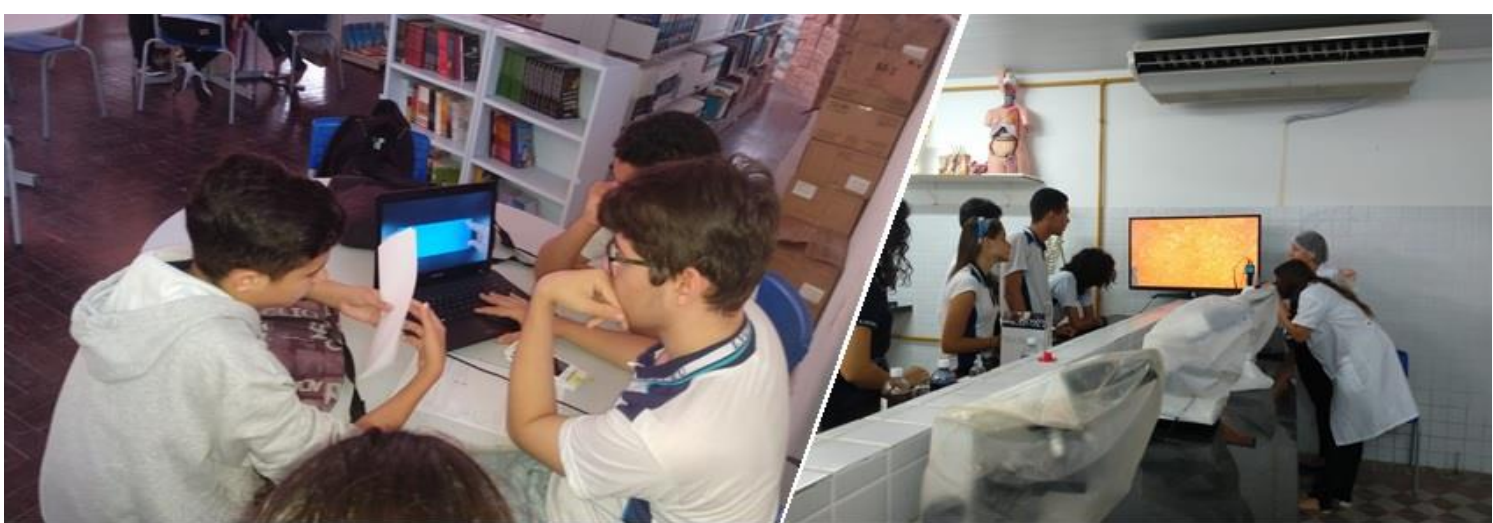

A

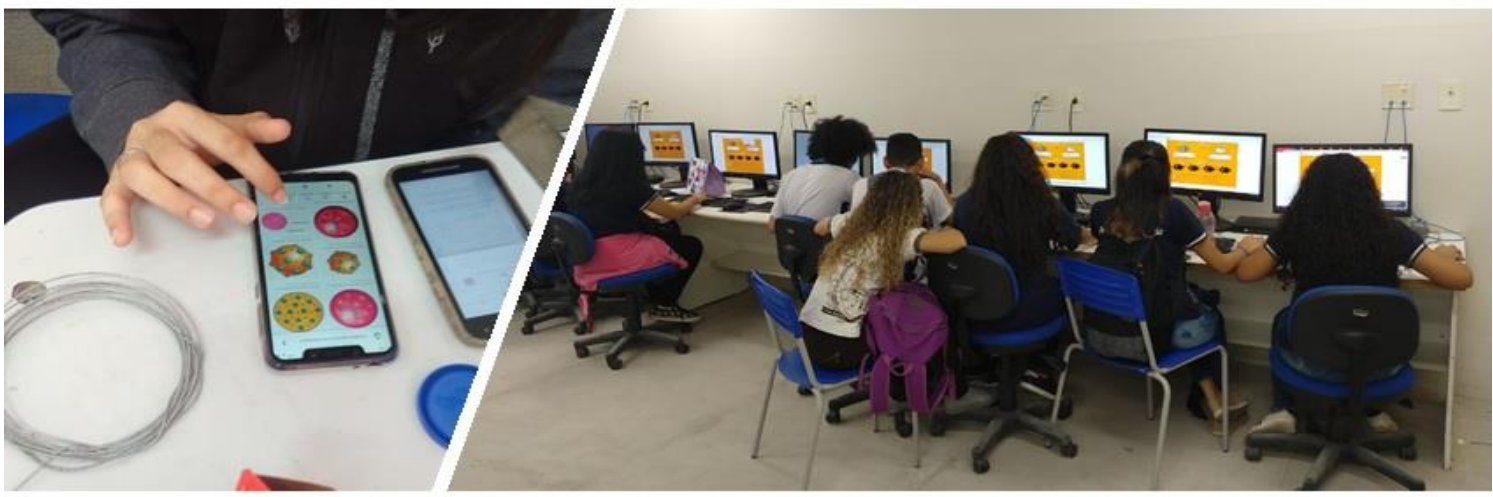

$\mathrm{C}$

Fonte: Dados da pesquisa

\section{$3^{\circ}$ Fase: Ligar os pontos}

Nesta etapa, os alunos relacionam os conceitos explorados e explicam com base em suas reflexões e descobertas, expressando a compreensão que alcançaram, demonstrando novas habilidades. Aqui, os processos de pensamento e de aprendizagem dos conteúdos utilizados, a interdisciplinaridade, as competências e habilidades são evidenciados, tornando-os conscientes do modo de utilizá-los na busca da solução do problema apresentado. É nesta faze onde todos os descritores de língua portuguesa e matemática puderam ser trabalhados em conjunto para dar sentido a situação problema. (Figura 6) 
Figura 6: A: Produção textual $I^{\circ}$ ano; B: Produção de modelos atômicos $3^{\circ}$ ano, C: Experimento prático,combustão e massa $3^{\circ}$ ano; D: Origames de DNA $3^{\circ}$ ano;
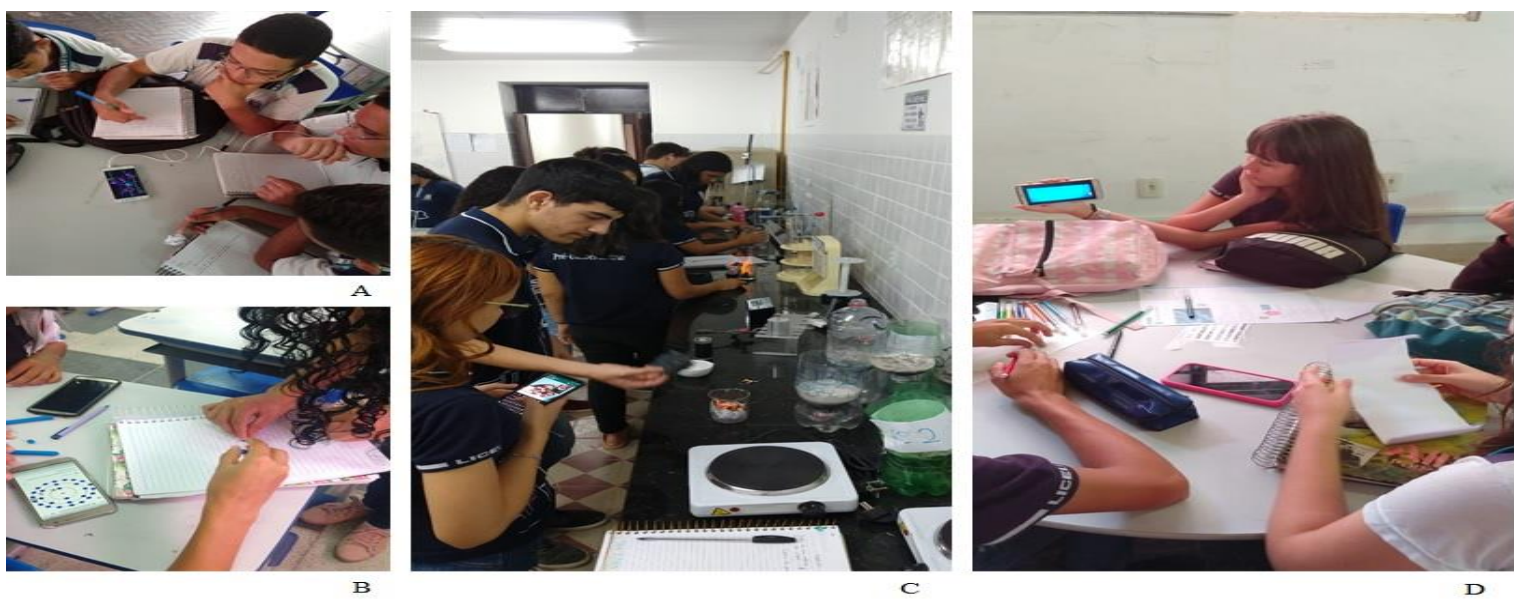

Fonte: Dados da pesquisa

\section{4을 Fase: Resolver Desafios}

É a etapa da contextualização dos conceitos já aprendidos, ou seja, é o uso dos conceitos em uma situação diferente da anterior. Nesta etapa os alunos se sentem desafiados e conseguem lançar mão de novas estratégias para chegar à solução do desafio é a etapa mais prática da SD, onde os descritores de matemática conseguem ser aplicados na resolução prática dos desafios, onde trabalhamos $\mathrm{D}_{3}$, Di3, Di7, D22, D31 e D33 em diferentes situações de SDs. (Figura 7)

Figura 7: $\mathrm{A}$ e D: identificando sistema $\mathrm{AOB} 3^{\circ}$ ano; B: Produção de modelos atômicos $3^{\circ}$ ano; C: entendendo probabilidade na genética $3^{\circ}$ ano;
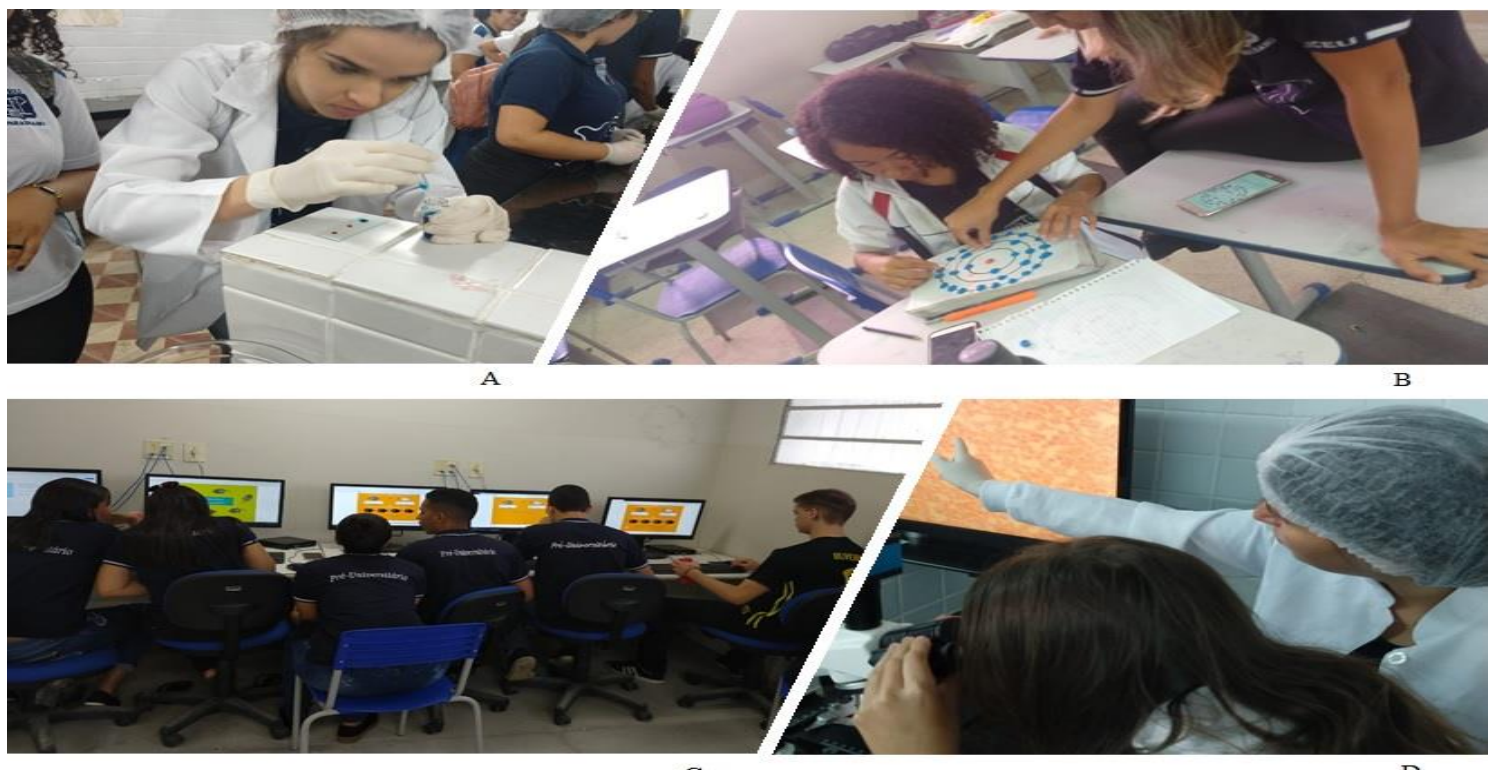

$\mathrm{C}$

Fonte: Dados da pesquisa 


\section{$5^{\circ}$ Fase: Passar de Fase}

Esta é a etapa de conclusão da Sequência Didática, é um momento em que o aluno se vê numa situação de reflexão crítica sobre seu próprio desenvolvimento cognitivo, o que ajuda a melhorar seus resultados. A avaliação ocorre durante o desenvolvimento da Sequência Didática, como diagnóstico que permite verificar se o aluno conseguiu compreender os conceitos trabalhados durante todas as etapas do processo, e assim avaliar o conhecimento e a compreensão de cada momento, além de conduzi-los a mensurar o seu entendimento dos principais conceitos e habilidades adquiridos durante todo o processo. (Figura 8)

Figura 8: Alguns resultados; A: Identificação do sistema AOB, B: Resolvendo probabilidade genética; C: Construção de modelos atômicos; D: Combustão e massa; E: Origames de DNA;

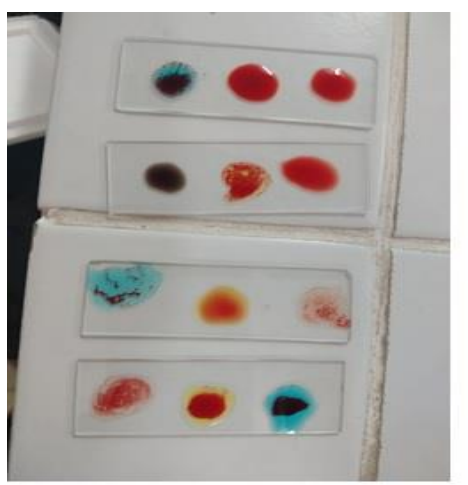

A

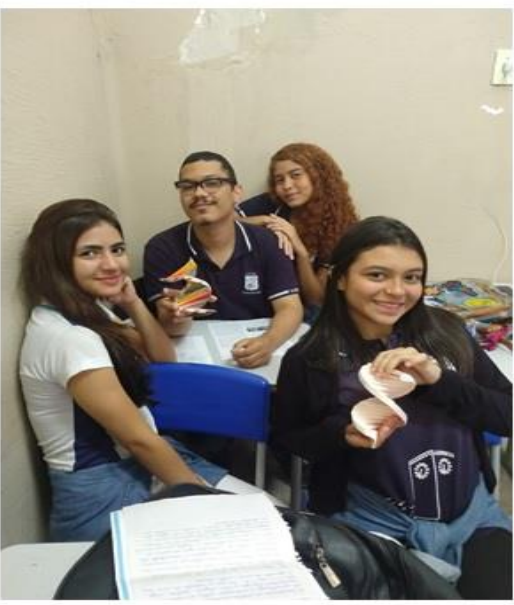

$\mathrm{E}$
B

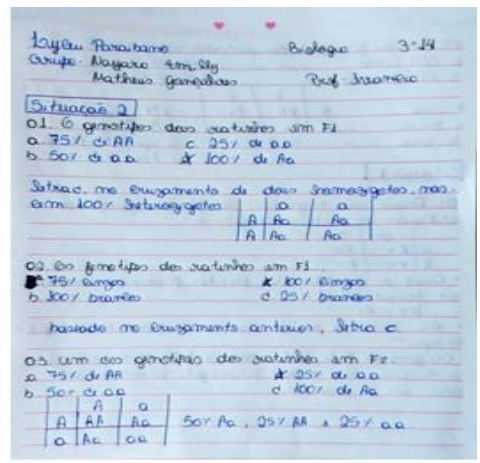

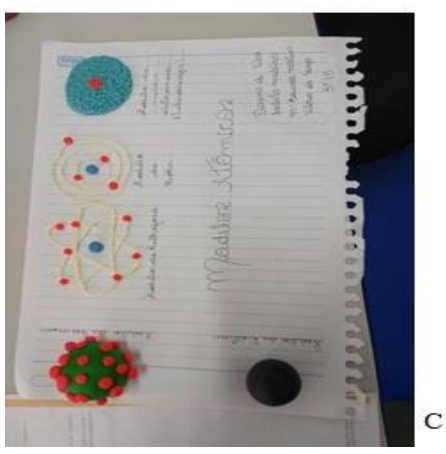

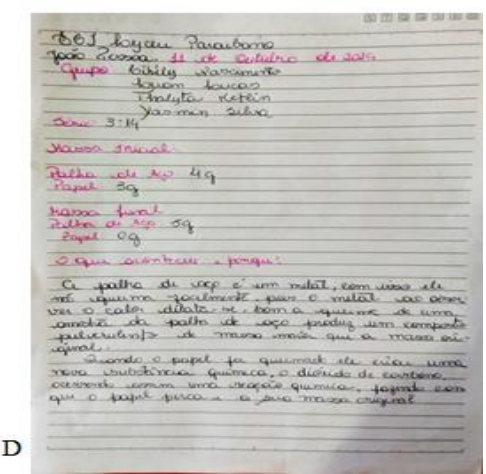

Fonte: Dados da pesquisa

O universo dos conteúdos digitais interativos foi a porta que permitiu aos alunos entrar em um mundo fantástico, cheio de recursos como simulações, infográficos, objetos ${ }_{3} \mathrm{D}$, mapas e legendas interativas, entre outros (Figura 9). Dessa forma, eles puderam explorar os temas curriculares usando ferramentas inovadoras, que fazem parte do mundo do aluno e foram trazidas para o cotidiano escolar. 
Figura 9: Modelos $3 \mathrm{D}$ utilizados em diferentes momentos. A: sala $3^{\circ}$ ano Esquema de meiose; B,C e D Esquema utilizados em sala de $\mathrm{I}^{\circ}$ ano, estrutura do DNA e duplicação de DNA;

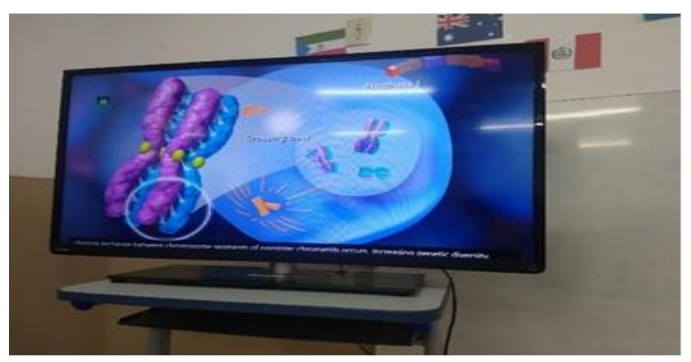

A

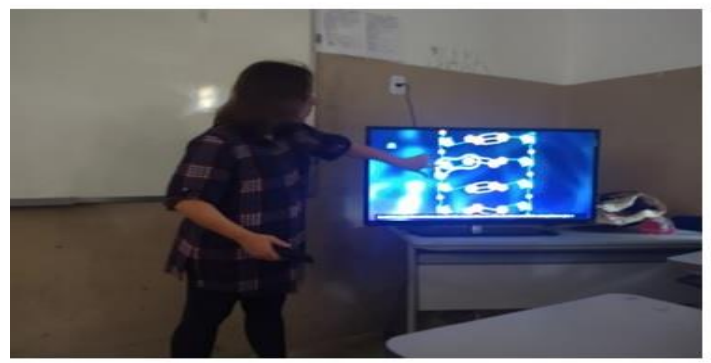

C
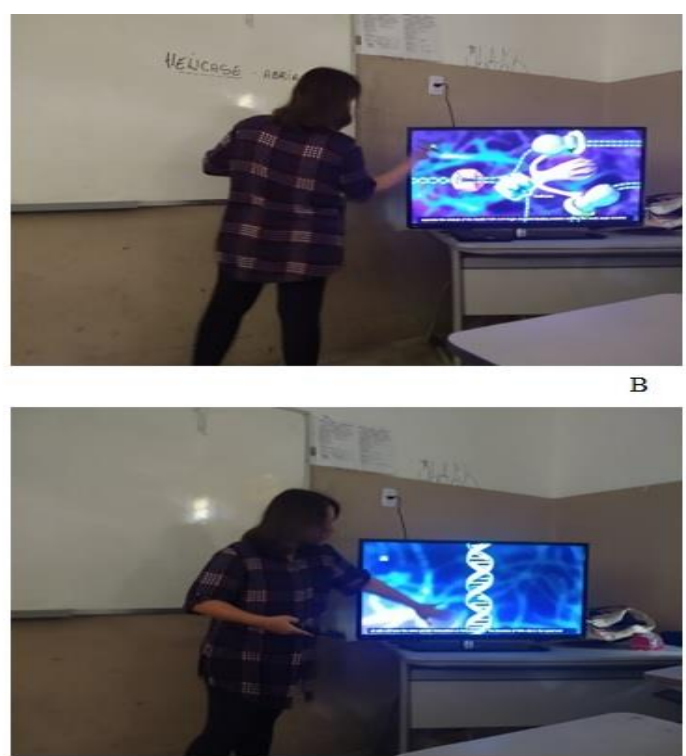

D

Fonte: Dados da pesquisa

A formação de grupos de atuação em torno da resolução de problemas por meio da pesquisa teve o potencial de estimular esses processos por um modo de aprendizado em que os estudantes puderam construir o conhecimento coletivamente a partir de propostas de trabalho em grupo (Figura io)

Figura ro: Trabalhos em grupos. A: Produção textual sala $\mathrm{I}^{\circ}$ ano; B: Aula prática de sangue, identificando sistema $\mathrm{AOB}$ no laboratório $3^{\circ}$ ano; C: Construção de modelos tridimencionais $3^{\circ}$ ano.
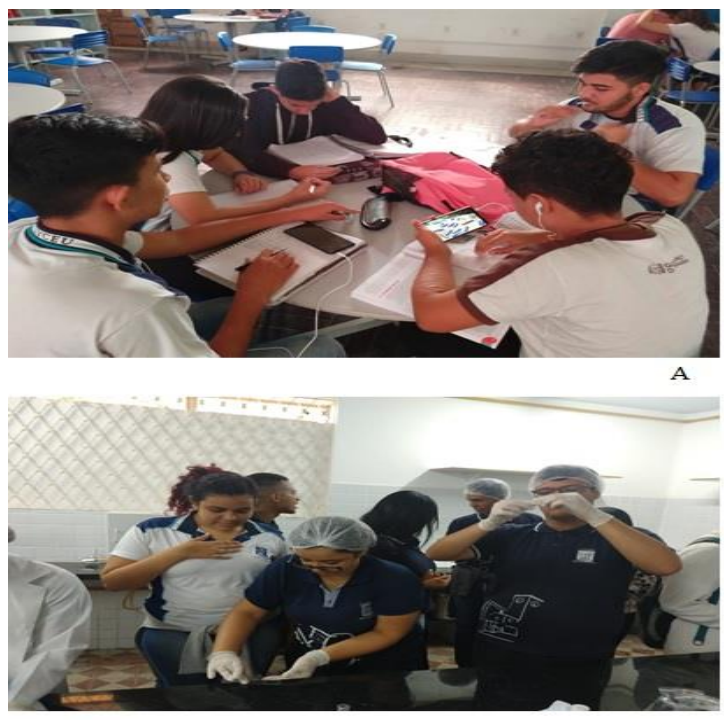

B

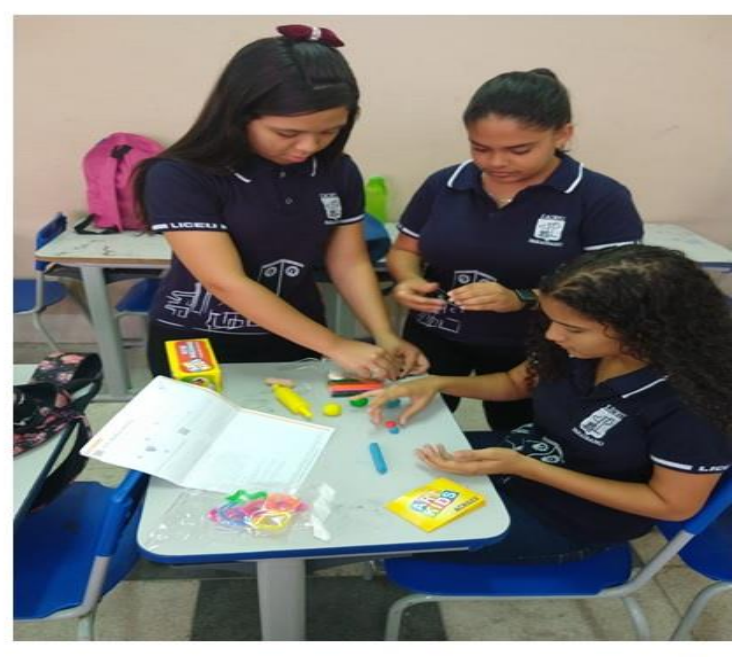

$\mathrm{C}$

Fonte: Dados da pesquisa 
A aplicação destas metodologias aliadas as ferramentas de tecnologia proporcionaram uma grande aproximação dentre a realidade digital que cerca os jovens em idade escolar, bem como agregar junto a eles novas formas de se estabelecer um conhecimento didatico e corente, frente a quantidade de informaçoes hoje ofertadas, sejam elas coerentes ou não. Uma vez que as didaticas e propostas ficaram claras para sua execução tanto para alunos quando para os professores podemos identificar e estabeler novos paramentos para uma "novo modelo de educação" aliando tecnologia e aprendizado.

Essa proposta de ensino conseguiu a valorização da aprendizagem significativa e ativa, possibilitando o desenvolvimento da autonomia e do espírito indagativo que aconteceu por meio de uma aprendizagem colaborativa onde o aluno foi o protagonista na construção do conhecimento, explorando cada título digital por meio do conteúdo adaptativo de forma interativa.

\section{CONSIDERAÇÕES FINAIS}

Com a aplicação do projeto conseguimos aliar iniciativa, criatividade, interesse intelectual e curiosidade na busca por conhecimento, desenvolvendo uma postura reflexiva e questionadora para a resolução de problemas, como base da investigação científica, onde o aluno pôde se responsabilizar pelo próprio aprendizado, de forma ativa, reflexiva e contínua. Utilizamos as tecnologias digitais em atividades pedagógicas com os alunos para despertar o interesse do aluno pelo problema apresentado, levando-o a se envolver com tema apresentado, desenvolvendo assim uma postura reflexiva e questionadora para a resolução de cada problema colocado, como base na investigação científica responsabilizando-o pelo próprio aprendizado, de forma ativa, reflexiva e contínua.

Percebemos, assim, a importância do uso das tecnologias digitais na educação e como o professor pode se apropriar dessas ferramentas de diferentes formas, tornando o processo de ensino-aprendizagem mais atrativo e significativo para o aluno.

As práticas didáticas com os livros juntamente com o programa desenvolvido neste projeto, são combustíveis facilitadores para que o professor implemente o uso da tecnologia no seu planejamento. Isso porque elas trazem situações concretas para o professor possa aplicar em sala de aula, sendo criadas para envolver os alunos com uma metodologia alinhada às questões atuais.

\section{REFERÊNCIAS}

AUSUBEL, D. P. Aquisição e retenção de conhecimentos: Uma perspectiva cognitiva. Trad. Lígia Teopisto. Plátano Edições Técnicas. Lisboa, 20oo. Disponível em: < 
http://www.uel.br/pos/ecb/ pages/> Acesso em II de ago. de 2019.

ALMEIDA, M. E. B. Maria Elizabeth de Almeida fala sobre tecnologia na sala de aula. Gestão Escolar. Edição 233. Jun./Jul., 2010. Disponível em: 〈http://gestaoescolar.abril.com.br/aprendizagem/ entrevista-pesquisadora-puc-sp- ecnologiasala-aula-568or2. shtml> Acesso em is de jan. de 2019.

ALMEIDA, M. E. B. A Educação a distância na formação continuada de gestores para a incorporação de tecnologias na escola. In: ETD - Educação Temática Digital, Campinas, v.ıo, n.2, p.186-202, jun. 2009. Disponível em: <www.fe.unicamp.br/revistas/ged/etd/ article/viewFile/1957/1794> Acesso em is de jan. de 2019.

ALMEIDA, M. E. B.; SILVA, M. G. M. Currículo, Tecnologia e Cultura Digital: espaços e tempos de Web Currículo. Revista e-curriculum, São Paulo, v.7 n.I abr., 20II. Disponível em: 〈http://revistas.pucsp. br/index.php/curriculum> Acesso em is de jan. de 2019.

BROUSSEAU, G. a cultura matemática é um instrumento para a cidadania. Revista Nova Escola, São Paulo, n. 228, dez. 2009. Disponível em: $<$ http://revistaescola.abril.com.br/formacao/cultura-matematica-instrumento-paracidadaniaguy-brousseau-calculo-518776.shtml?page=2>-Acesso em 8 de abr. de 2019.

BSCS - Biological Sciences Curriculum Study. Disponível em: <http://bscs.org/bscs-5einstructional-model> Acesso em os de jun. de 2019.

CASTELLS, Manuel. Creatividad, innovación y cultura digital. Un mapa de sus interecciones. Revista Telos - Cuadernos de Comunicación e Innovación - Dossier Telos 2009.

MORAN, J. M. Uma lenta evolução (Entrevista, Guia de Educação a Distância) Ano I2, no I2, São Paulo: Segmento, 2015.

PERRENOUD, P. Dez novas competências para ensinar: convite à viagem. Porto Alegre: ArtMed, 200o.

PRADO, C. Política da Cultura Digital. In: COHN, Sérgio; SAVAZONI, Rodrigo (orgs). Cultura digital.br. Rio de Janeiro: Azougue Editorial, 2009. p. 45.

PROGRAMA INSPIRA DIGITAL : metodológico e orientações didáticas / [organização] EvoBooks. -- São Paulo : EvoBooks, 2016.

VALENTE, J. A. Pesquisa, comunicação e aprendizagem com o computador. O papel do computador no processo ensino aprendizagem. In: Tecnologia, Currículo e Projetos. 2008. Disponível em: 〈http://portal.mec.gov.br/seed/arquivos/pdf/Isf.pdf> Acesso em is de jan. de 2019.

ZABALA, Antoni. A prática educativa. Tradução: Ernani F. da F. Rosa. Porto Alegre: ArtMed, 1998. p. 18. 